\title{
Developing a framework for teaching clinical reasoning skills to undergraduate physiotherapy students: A Delphi study
}

Gisela Sole BSC (Physio), MSC (Med) Exercise Science, PhD, FNZCP

Associate Dean Undergraduate Studies, School of Physiotherapy, Centre for Health, Activity and Rehabilitation Research, University of Otago, Dunedin, New Zealand

Margot Skinner DipPhty, MPhEd, PhD, FNZCP

Deputy Dean, School of Physiotherapy, Centre for Health, Activity and Rehabilitation Research, University of Otago, Dunedin, New Zealand

Leigh Hale BSC (Physio), MSC, PhD, FNZCP

Professor and Dean, School of Physiotherapy, Centre for Health, Activity and Rehabilitation Research, University of Otago, Dunedin, New Zealand

Clinton Golding MA, DipProfEthics, PhD

Deputy Head of Department, Higher Education Development Centre (HEDC), University of Otago, Dunedin, New Zealand

\section{ABSTRACT}

Students may find it confusing when methods and principles of clinical reasoning vary in different parts of a curriculum. A consistent framework between laboratory and clinical practice, and across the curriculum should be designed to facilitate student learning. The aim of this study was to identify key elements that academic and teaching staff consider to be important for teaching clinical reasoning to undergraduate physiotherapy students at the University of Otago, New Zealand. Educators ( $n=41)$ involved in Year 2 to 4 teaching for at least one academic year across the School of Physiotherapy's centres and hubs were invited to participate. A Delphi study was used to reach consensus about principles of clinical reasoning. There was consensus that clinical reasoning is an ongoing, complex and systematic process that is both collaborative and interactive. The World Health Organization International Classification of Function was the model considered most relevant for students to both gather and interpret information from the patient, and to plan and apply management. While students are expected to rely mainly on hypothetico-deductive reasoning systems, pattern recognition may develop with integration of theoretical knowledge and clinical practice. This project enabled physiotherapy educators to share information across their different geographical and contextual areas, and to reach consensus about elements considered important for teaching clinical reasoning to undergraduate students.

\section{Sole, G., Skinner, M., Hale, L., \& Golding, C. (2019). Developing a framework for teaching clinical reasoning skills to undergraduate physiotherapy students: A Delphi study. New Zealand Journal of Physiotherapy, 47(1), 49-58. https://doi. org/10.15619/NZJP/47.1.06}

Key Words: Clinical Reasoning, Entry-level Physiotherapy, Educators

\section{INTRODUCTION}

Clinical reasoning forms the basis of autonomous, competent and effective health professional practice, yet is a challenge to teach and learn. To learn the multidimensional and complex nature of clinical reasoning, students need to gain a firm knowledge base, effective cognitive processes and the ability to monitor thinking processes (Ajjawi \& Smith, 2010; Higgs $\&$ Jones, 2008). Critical thinking and clinical reasoning are developed at rates specific to the individual (Ajjawi \& Smith, 2010; Christensen et al., 2017). Furthermore, development of these kinds of thinking is influenced by the individual beliefs, preferences and experiences of the students as well as of the various teachers and clinicians involved in their professional education (Christensen et al., 2017; Cruz, Moore, \& Cross, 2012). Overall, health professional students need support to gain the ability to make autonomous decisions in ambiguous and complex contexts (Ajjawi \& Smith, 2010).

Students' development of clinical reasoning skills is not automatic and needs to be explicitly taught, assessed and reflected upon by both teachers and students (Ajjawi \& Smith, 2010; Rencic, Trowbridge, Fagan, Szauter, \& Durning, 2017). A range of valid and reliable methods are used for teaching the concepts, principles, skills and knowledge required for clinical reasoning. Principles of clinical reasoning may be addressed explicitly in defined courses, lectures or other contexts as well as implicitly within the curriculum and in clinical practice (Christensen et al., 2017). Such teaching is embedded in lectures, practical laboratories and clinical practice in the physiotherapy programme.

There is wide variability in definitions and methods of teaching clinical reasoning across physiotherapy and other healthcare curricula, and a lack of consistency across programmes is common (Christensen et al., 2017; Gruppen, 2017; Huhn, Gilliland, Black, Wainwright, \& Christensen, 2018). Traditionally, there has been differentiation between the fields of cardiopulmonary rehabilitation, neurorehabilitation and musculoskeletal rehabilitation. While there are common principles for concepts of reasoning across these key areas of 
physiotherapy practice, each area may be taught using different models and terminology and with different teaching contexts (Christensen et al., 2017). There may also be differences between concepts used within classroom teaching and clinical settings.

Variability in the terminology and methods of teaching clinical reasoning can confuse students as they attempt to acquire their profession-specific, autonomous skills (Cruz et al., 2012; Gruppen, 2017). This confusion can arise, for example, when each teacher or paper (course) asks for something different from students or uses the same terms to ask for different things. As a consequence, students are pulled in multiple directions and may fail to develop a core framework of clinical reasoning (Golding, Wilkinson, \& Gamble Blakey, 2018). Thus, defining elements of clinical reasoning that are considered important for educators in the classroom and clinical practice as well as across all fields of physiotherapy should facilitate students' learning of physiotherapy (Ajjawi \& Higgs, 2012).

The Bachelor of Physiotherapy at the University of Otago is a four-year programme. The first year focuses on health sciences; Years 2 and 3 are predominantly physiotherapy-based with components of clinical practice and Year 4 is a clinical- and research-based year. The curriculum in Years 2 and 3 uses an integrated teaching model, rather than being based around the three traditional fields of physiotherapy (cardiopulmonary rehabilitation, neurorehabilitation and musculoskeletal rehabilitation). The focus of teaching and learning is on personcentred management. In line with contemporary directions within health professions, guided self-directed learning receives an increasing focus (Brydges, Dubrowski, \& Regehr, 2010; Hoogenes et al., 2015). The fourth (final) year of the programme focusses on clinical practice, consisting of four six-week placements in an integrated model within primary, secondary and tertiary healthcare settings. In addition, students complete a small group research project during a six-week rotation within the academic year. Since 2013, the option has also existed for top-performing students to undertake an honours programme. The Year 4 programme is provided at the University of Otago's campuses in Dunedin, Christchurch and Wellington, and a number of hubs across New Zealand. The majority of students are thus posted outside the geographical confines of Otago during Year 4, increasing their potential for exposure to a wide range of clinical educators in the different clinical contexts and therefore other ways of thinking about clinical reasoning.

A common framework for clinical reasoning within the programme has become even more important with the curriculum having moved towards an integrated approach to learning and teaching. Additionally, increased awareness by educators (i.e. lecturers, tutors, clinical educators and supervisors) of a range of models used for teaching clinical reasoning skills across the programmes should be built on an agreed concept of the clinical reasoning process. It was agreed an increased awareness of the different models or approaches used across the programme could assist the educators to facilitate a clearer understanding by students of the process (Christensen et al., 2017).

As a basis for curriculum refinement, we considered it important to explore various clinical reasoning frameworks and concepts that might be embedded within the programme. It was agreed such insights would lead to a preferred model that would be the shared concept. The aim of this study was to identify the key elements that all academic and teaching staff considered to be important for teaching clinical reasoning to undergraduate physiotherapy students.

\section{METHODS}

\section{Design}

The study involved a three-round Delphi survey to gain consensus on key elements for teaching clinical reasoning (Hasson, Keeney, \& McKenna, 2000; Keeney, Hasson, \& McKenna, 2011). A Delphi survey is an iterative, multi-stage process, collating the views of the participants in order to provide group consensus (Hasson et al., 2000). It has been used extensively to gain consensus about important aspects of health professional education (Chipchase et al., 2012; McMahon, Cusack, \& O'Donoghue, 2014; Swamy, Venkatachalam, \& McLachlan, 2014). A Delphi survey has the following advantages relevant to this research study. Firstly, it maintains anonymity among participants and allows them time to consider their responses. Secondly, it allows involvement of participants from different geographical locations and academic roles by using emails and online questionnaires. This was considered important as students undertake clinical placements across various areas of New Zealand and have a range of physiotherapist supervisors. Finally, the Delphi technique uses statistical analysis to summarise the data (Hsu \& Sandford, 2007).

\section{Participant recruitment}

All academic staff, clinical educators and clinical supervisors ( $n=41$ ) working for the School of Physiotherapy who had been involved in Year 2 to 4 teaching for at least one full academic year were invited to participate. Clinical educators are physiotherapists employed by the University of Otago to oversee students' performance on clinical placements. Clinical supervisors work with students on a daily basis as part of their employment at the clinical location, such as in District Health Boards, aged care facilities or private practices. Academic staff, clinical educators and clinical supervisors involved in lecturing, laboratory supervision and/or clinical teaching in the School of Physiotherapy's three clinical centres and their associated clinical hubs were emailed information regarding the study, including an online link to the questionnaire. All recipients of the email were encouraged to forward the information about the study to other clinical supervisors who may not have been included in the initial distribution list. A snowballing method to complement recruitment was thus employed. The university's Human Ethics Committee approved the study (D14/096), and informed consent was taken as agreement to participate in and complete the online Delphi survey.

We used online questionnaires administered through SurveyMonkey software (San Mateo, CA, USA). The same procedures for recruitment were used for each of the three rounds. Each round of the Delphi survey was open for four weeks, with three weeks between each stage. Emails were sent to potential participants after the start of each round to remind them that the survey was still open. Demographic data were collected for each round, including gender, years of practice since graduation as a physiotherapist, main field of current 
practice, highest academic qualification and current teaching role. Questionnaires were only identifiable by a code, and all data were kept on a password protected computer system to ensure confidentiality.

Round 1: The research team developed the core questions to be used in Round 1 of the Delphi survey. Three members of the team each had more than 20 years' experience in physiotherapy education, including leadership in designing university papers; and provision of lectures, laboratories and clinical education. The fourth team member had extensive experience in higher education. Four open-ended questions or prompts were developed by the team (Table 1). Participants were asked these questions and invited to provide detailed responses, which included providing examples. Eleven participants returned their responses.

\section{Table 1: Questions and prompts included in Delphi Round 1 and included in subsequent rounds}

\section{Question}

1. How would you describe "clinical reasoning"? Please give concrete examples

2. Describe how you go about clinical reasoning in your own practice. Please provide concrete examples.

3. What clinical reasoning do you expect at entry into Year 2?

4. What clinical reasoning do you expect from a student at the end of a) Year 2, b) Year 3, c) Year 4

The responses were downloaded from SurveyMonkey into a Microsoft Excel spreadsheet and were analysed independently by two members of the research team. Template analysis was employed: a form of thematic analysis, in which a coding template is developed on the basis of a subset of data, which is then applied to further data (Brooks, McCluskey, Turley, \& King, 2015). The researchers read and re-read the open-ended responses, and coded and summarised key characteristics or items into themes. The themes and their key characteristics or items were discussed at a face-to-face meeting of the research team. The final agreed list was prepared as a questionnaire to be used for Rounds 2 and 3 of the Delphi survey (see Table 2). Participants' demographic data were analysed descriptively (median and ranges) for each round using SPSS v22 (IBM Corp. Released 2013. Armonk, NY: IBM Corp.).

Round 2: All potential participants were emailed an electronic link to the second questionnaire. Participants were asked to rate the importance of each characteristic or item in the questionnaire on a five-point Likert scale ( 5 = strongly agree; 4 = agree; 3 = neutral; 2 = disagree; 1 = strongly disagree). The option of "don't know" (=0) was also provided for each item. For each theme an option was provided for participants to list further characteristics of clinical reasoning that had not yet been included.

Median ratings were calculated for each item, and a record of whether there was consensus about each item was made. Consensus was determined if the following pre-specified criteria were met: median rating $\geq 4$ and $70 \%$ or more of participants rated the item as 4 or 5 on the Likert scales. This meant that for each statement $\geq 70 \%$ of participants "agreed" or "strongly agreed" that the category or item should be considered as a descriptor or component of undergraduate students' clinical reasoning skills. All items from Round 2 were included in Round 3 , even if consensus had not been reached. Free text comments for Round 2 were analysed thematically and included as an additional item for Round 3.

Round 3: Participants were provided with the group summary ratings (median and percentage agreement) for each item from Round 2 and asked to re-rate their level of agreement using the five-point Likert scale. They were also invited to add further comments. Response data were then re-analysed for levels of agreement and consensus using the same methods as for Round 2 .

\section{RESULTS}

Demographics for participants are shown in Table 3. Responses from the questions posed in Round 1 were categorised into the following themes for Rounds 2 and 3: (1) Definition of clinical reasoning; (2) Processes included in clinical reasoning; (3) Personal attributes, knowledge and skills that provide a foundation and pre-requisites for clinical reasoning; (4) Models that provide a framework for clinical reasoning; (5) Essential components for clinical reasoning; (6) Patient-related factors; (7) Physiotherapist-related factors; and (8) Other factors and sources that influence clinical reasoning. Key characteristics or items of each theme are presented in Table 3.

Based on respondents' suggestions in Round 2, the following items were added for Round 3:

- Table 2, number 1: "Complex", "systematic" and "intuitive" to the definition of clinical reasoning.

- Table 2, number 2: "Collecting appropriate information" to processes of clinical reasoning.

- Table 2, number 5: "Good communication skills" to essential components of clinical reasoning.

- Table 2, number 7: "Reflective skills" to physiotherapistrelated factors.

- Table 2, number 8: "Best available evidence" to factors influencing clinical reasoning.

Analysis of Round 3 data found there was consensus for most items defined following Round 1, i.e. that these were considered important for undergraduate physiotherapy students. Consensus was reached for hypothetico-deductive reasoning and the World Health Organization (WHO) International Classification of Function (ICF) model (World Health Organization, 2002) to be used to provide a framework for clinical reasoning.

\section{DISCUSSION}

This study identified key elements that academic and teaching staff considered important for teaching clinical reasoning to undergraduate physiotherapy students. The study provided an opportunity to collate views and methods of teaching clinical reasoning skills across the physiotherapy fields contributing to the Bachelor of Physiotherapy and Bachelor of physiotherapy 


\begin{tabular}{|c|c|c|c|}
\hline \multicolumn{2}{|c|}{ Round 2} & \multicolumn{2}{|c|}{ Round 3} \\
\hline $\begin{array}{c}\text { Agreement* } \\
(\%)\end{array}$ & Median & $\begin{array}{c}\text { Agreement* } \\
(\%)\end{array}$ & Median \\
\hline
\end{tabular}

$(\%)$

$\begin{array}{cccc}88.9 & 5 & 100.0 & 5 \\ 92.6 & 5 & 94.1 & 4 \\ - & - & 88.2 & 5 \\ - & - & 88.2 & 4 \\ - & - & 76.5 & 4 \\ 48.1 & 3.5 & 47.1 & 4 \\ & & & \\ 96.3 & 5 & 100.0 & 5 \\ 96.3 & 5 & 100.0 & 5 \\ 96.3 & 5 & 100.0 & 5 \\ 96.3 & 5 & 94.4 & 5 \\ 77.8 & 5 & 94.4 & 4 \\ 96.3 & 5 & 94.4 & 5 \\ - & - & 94.4 & 5 \\ 81.5 & 4 & 77.8 & 4\end{array}$

5

5

4

1. A definition of clinical reasoning should include the following:

An ongoing process

A collaborative and interactive process

A complex process

A systematic process

An intuitive process

An art †

2. Processes of clinical reasoning include:

Decision-making

Weighing evidence

Formulating, confirming and negating hypotheses

Prioritising information

Clinical pattern recognition

Problem-solving

Collecting appropriate information

Goal-setting

3. The following personal attributes, knowledge and skills provide a foundation and prerequisites for clinical reasoning:

Awareness of one's own thinking and reasoning process

(meta-cognition)

The ability to integrate (link) information

Critical thinking

Physiotherapy-specific knowledge

Knowledge of relevant biomedical sciences

Inter-personal communication skills

Knowledge of the evidence base

Knowledge about oneself (such as personal values, cultural values, the

ability to reflect on experiences)

Constant inquisitive mind

Clinical experience

Physiotherapy-specific practical skills

Inter-personal relationship skills

Adherence to best practice guidelines $†$

Professional intuition +

88.9

96.3

92.6

92.6

85.2

81.5

85.2

77.8

74.1
66.7

81.5

63.0

66.7

59.3
100.0

100.0

100.0

100.0

94.4

88.9

88.9

83.3

83.3

83.3

77.8

72.2

66.7

38.9

88.9

77.8

66.7

61.1

55.6

50.0

38.9

37.0

3.5

3

96.3

5

100.0

100.0

100.0

100.0

4. The following models or tools provide a framework for clinical reasoning for physiotherapists:

Weighing evidence 


\begin{tabular}{|c|c|c|c|c|}
\hline & \multicolumn{2}{|c|}{ Round 2} & \multicolumn{2}{|c|}{ Round 3} \\
\hline & $\begin{array}{c}\text { Agreement* } \\
(\%)\end{array}$ & Median & $\begin{array}{c}\text { Agreement* } \\
(\%)\end{array}$ & Median \\
\hline Differential diagnosis & 88.9 & 5 & 100.0 & 4 \\
\hline Problem identification & 96.3 & 5 & 100.0 & 5 \\
\hline Re-evaluation & 96.3 & 5 & 100.0 & 5 \\
\hline Clinical judgement & 92.6 & 5 & 94.4 & 5 \\
\hline Professional knowledge & 92.6 & 5 & 88.9 & 5 \\
\hline Pattern recognition & 66.7 & 4 & 88.9 & 4 \\
\hline Defining indications, contraindications and precautions & 81.5 & 4 & 88.9 & 4 \\
\hline Self-reflection & 88.9 & 4.5 & 83.3 & 5 \\
\hline Good communication skills & - & - & 83.3 & 5 \\
\hline Scope of practice + & 51.9 & 4 & 61.1 & 4 \\
\hline \multicolumn{5}{|c|}{ 6. Clinical reasoning includes considerations of the following patient-related factors: } \\
\hline \multicolumn{5}{|l|}{ The patient's: } \\
\hline - beliefs & 92.6 & 5 & 100.0 & 5 \\
\hline - culture & 92.6 & 5 & 100.0 & 5 \\
\hline - preferences & 88.9 & 5 & 100.0 & 5 \\
\hline - social factors & 96.3 & 5 & 100.0 & 5 \\
\hline - physical status & 96.3 & 5 & 100.0 & 5 \\
\hline - mental status & 96.3 & 5 & 100.0 & 5 \\
\hline - body structure and functional limitations (impairments) & 96.3 & 5 & 100.0 & 5 \\
\hline - activity level (function) & 96.3 & 5 & 100.0 & 5 \\
\hline - symptom behaviour & 96.3 & 5 & 100.0 & 5 \\
\hline - decision-making ability & 88.9 & 4 & 94.4 & 4 \\
\hline - safety & 92.6 & 5 & 94.4 & 5 \\
\hline - ability to communicate & 85.2 & 4 & 94.4 & 4 \\
\hline - co-morbidities & 96.3 & 5 & 94.4 & 5 \\
\hline - level of empowerment & 88.9 & 4 & 94.4 & 4 \\
\hline - health literacy & 77.8 & 4 & 88.9 & 4 \\
\hline - environmental control & 77.8 & 4.5 & 88.9 & 4 \\
\hline 7. Clinical reasoning includes considerations of the following physio & -related factors & & & \\
\hline \multicolumn{5}{|l|}{ The physiotherapist's: } \\
\hline - risk assessment & 96.3 & 5 & 100.0 & 5 \\
\hline - knowledge & 96.3 & 5 & 100.0 & 5 \\
\hline - reflective skills & - & - & 94.4 & 5 \\
\hline - clinical skills & 85.2 & 5 & 88.9 & 5 \\
\hline - expertise & 77.8 & 5 & 83.3 & 4 \\
\hline - safety & 77.8 & 4 & 77.8 & 4 \\
\hline \multicolumn{5}{|c|}{ 8. Clinical reasoning is influenced by the following other factors and sources: } \\
\hline Medical or clinical notes, referrals and other investigations & 96.3 & 5 & 100.0 & 5 \\
\hline Context of the environment, including policy & 81.5 & 4 & 94.4 & 4 \\
\hline Best available evidence & - & - & 94.4 & 5 \\
\hline Discussion/consultation with others & 77.8 & 4 & 83.3 & 4 \\
\hline Discussion/consultation with educators & 81.5 & 4 & 77.8 & 4 \\
\hline Discussion/consultation with other students/peers & 70.4 & 4 & 72.2 & 4 \\
\hline Clinical environment (e.g. acute care, community care and self-care) & 85.2 & 4 & 72.2 & 4 \\
\hline Equipment and other resources & 74.1 & 4 & 72.2 & 4 \\
\hline
\end{tabular}

Notes: SOTAP, Subjective, objective, treatment, analysis, plan; *Agreement was defined as $70 \%$ or more of participants rating the item as 4 or 5 on the Likert scales; +Elements or items not reaching consensus for being important for teaching and learning clinical reasoning skills at undergraduate physiotherapy levels ( $<70 \%$ of participants rating the item as a 4 or 5 on the Likert scales) 
Table 3: Demographics of participants

\begin{tabular}{|c|c|c|c|c|c|c|}
\hline & \multicolumn{2}{|c|}{ Round $1(n=11)$} & \multicolumn{2}{|c|}{ Round $2(n=27)$} & \multicolumn{2}{|c|}{ Round $3(n=18)$} \\
\hline Men/women, number (\%) & \multicolumn{2}{|c|}{$3 / 8(27 / 63)$} & \multicolumn{2}{|c|}{$8 / 19(30 / 60)$} & \multicolumn{2}{|c|}{$4 / 14(22 / 78)$} \\
\hline \multirow{2}{*}{$\begin{array}{l}\text { Number of years since completion of entry- } \\
\text { level education (median, range) }\end{array}$} & \multicolumn{2}{|c|}{$22(15-40)$} & \multicolumn{2}{|c|}{$17(4-40)$} & \multicolumn{2}{|c|}{$19(11-40)$} \\
\hline & Number & $\%$ & Number & $\%$ & Number & $\%$ \\
\hline \multicolumn{7}{|l|}{ Main field of clinical practice } \\
\hline Cardiopulmonary rehabilitation & 2 & 18 & 2 & 7 & 3 & 17 \\
\hline Neurorehabilitation & 2 & 18 & 8 & 30 & 3 & 17 \\
\hline Musculoskeletal rehabilitation & 7 & 64 & 8 & 30 & 6 & 33 \\
\hline General* & - & & 9 & 33 & 6 & 33 \\
\hline \multicolumn{7}{|l|}{ Academic level } \\
\hline Diploma/Bachelor & 1 & 9 & 6 & 22.2 & 5 & 27.8 \\
\hline Post-graduate certificate or diploma & 1 & 9 & 4 & 14.8 & 2 & 11.1 \\
\hline Masters & 4 & 36 & 7 & 25.9 & 4 & 23.5 \\
\hline $\mathrm{PhD}$ & 5 & 46 & 10 & 37 & 7 & 35.3 \\
\hline
\end{tabular}

Notes: PhD, Doctor of Philosophy; *Participants were classified as "general" if they indicated that or indicated two or more of the above fields as being their clinical practice areas

(honours) programmes at the University of Otago. Collectively, it was agreed that clinical reasoning is an ongoing, complex and systematic process that is collaborative and interactive. Such reasoning includes decision-making at all levels of assessment and management, including formulating, confirming and negating hypotheses, recognising clinical patterns, problemsolving and goal setting. There was consensus amongst the respondents that the WHO ICF model can be used as a framework for teaching and practising clinical reasoning across all fields, allowing consideration for patient- and physiotherapist-related factors, and other contextual-related factors.

Participants considered various forms of profession-specific knowledge to be important, including physiotherapy and biomedical, and the research evidence base (Table 2, number 3). Furthermore, personal knowledge in terms of culture, values, self-awareness and reflection skills achieved consensus as important for clinical reasoning; knowledge about oneself may be increasingly important to develop resilience, self-esteem and perseverance as a clinician and student (Colthart et al., 2008; O'Connell, Gardner, \& Coyer, 2014; Patton, Higgs, \& Smith, 2018). The importance of attaining relevant knowledge has previously been argued to be at the centre of clinical reasoning, and thus, in a sense, our findings concur with this (Gruppen, 2017).

A wide range of processes and components of clinical reasoning skills were considered important. Broadly, these could be grouped within Kahneman's (2011) two metaphorical systems of critical thinking: thinking "fast" (System 1) and thinking "slow" (System 2). Pattern recognition and professional intuition are most likely "fast" thinking processes. Professional or clinical intuition has been described as a "feeling" and may also overlap with "clinical gut feeling" (Langridge, Roberts, \& Pope, 2016; Peters et al., 2017; Van den Bruel, Thompson, Buntinx, \& Mant, 2012). Hypothetico-deductive reasoning is a "slow" thinking processes, being analytical, conscious and conceptual (Peters et al., 2017). This reasoning process generates hypotheses at multiple levels from the first patient encounter, and then moves towards assessment of the patient's problem and diagnosis, establishes goals and planning, and provision of interventions (Levett-Jones et al., 2010). Hypothetico-deductive reasoning and the WHO ICF model as a biopsychosocial framework were highly rated by the respondents.

Respondents considered that clinical reasoning should be partially defined as an "intuitive process", which is a "fast thinking" process (Table 2, number 1). Yet, they did not reach a consensus that "professional intuition" $(38.9 \%)$ is a required attribute or skill expected for students (Table 2, number 3 ). In contrast, consensus was achieved for pattern recognition (Table 2, number 5, Round 3; 88.9\%). Thus, within the "fast" thinking processes, "pattern recognition" was considered more important than "professional intuition".

At undergraduate levels, it is more likely that the "slow" thinking processes develop first, based on progressively acquired knowledge. Increasing reliance on pattern recognition and professional intuition has been described as being directly 
associated with increased clinical exposure (Langridge, Roberts, \& Pope, 2015; Langridge et al., 2016). Use of the "fast thinking" processes, particularly clinical intuition, may thus be expected to be increasingly important during the final year of study or when practising as a graduate physiotherapist.

The results highlight that the various reasoning models are influenced by patient-, physiotherapist- and contextual-related factors. Our findings support those of a qualitative study involving entry-level physiotherapy students, which highlighted their understanding of clinical reasoning as a "context dependent phenomenon" (Cruz et al., 2012, p. 552). In line with a person-centred approach, the biological, psychological and social elements were considered by our participants, as were considerations of general health issues (co-morbidities) that may influence decision-making. In terms of physiotherapyrelated factors, the level of knowledge, and clinical and reflective skills were important, as well as the safety of both the physiotherapist/student and the patient.

Interpersonal communication and relationship skills were also considered important for teaching and learning clinical reasoning skills. This reflects the multidimensional and collaborative elements of acquisition of clinical reasoning skills, as these are enhanced by verbalising thinking processes and willingness to accept and respond to feedback (Patton et al., 2018). Similarly, multi-directional discussion and consultation, such as with educators, peers and others, were considered to influence the acquisition of clinical reasoning. Multi-directional consultation has also been highlighted as important from patients' perspectives: they valued physiotherapists' attributes that facilitate a person-centred approach, and their ability to understand people and to relate to them (Kidd, Bond, \& Bell, 2011). Students who have challenges communicating with their educators may find it difficult to acquire the required reasoning skills. The reverse may also hold true, namely where educators have challenges with communicating or deconstructing their own thought processes with students. Thus, bilateral awareness and reflection on communication and relationship skills are needed to optimise students' continued development.

Educators should be aware that their own clinical reasoning is strongly influenced by a range of factors. Such factors include their level of expertise, clinical education and experience as well as their beliefs regarding clinical practice, education and pedagogy, and their interpretation of the evidence in addition to their personal, cultural and ethical values and communication skills (Langridge et al., 2015; Patton et al., 2018). Self-awareness is thus required both by students and by educators to fully achieve the necessary critical analysis, communication and clinical skills (Langridge et al., 2016). Educators need to remain flexible and familiar with the wide range of elements influencing clinical reasoning. They should be willing and able to discuss various approaches that may be possible within the clinical context.

Other contextual factors of importance for clinical reasoning included the availability of resources and equipment, the clinical environment, referral, and current policies. Therefore, clinical reasoning was described to incorporate an outwards focus from the patient, including consideration of the influences of broader healthcare systems on assessment and management of the patient. Ahlsen, Mengshoel, Bondevik and Engebretsen (2018) recently articulated such an interpretation of the patient's complexity as "clue production, plot building and continuous weighing of different scenarios" (p. 44). The complexities highlight the challenges faced by students and educators to develop the knowledge and skills, not only of the biopsychosocial and profession-specific domain, but also of the wider healthcare system. Those competencies need to be acquired and demonstrated within the confines of the four-year programme.

A recent concept analysis described clinical reasoning in various health disciplines (Huhn et al., 2018). The analysis defined key elements of clinical reasoning as including "antecedents", "consequences" and "attitudes". Antecedents are events or processes that occur predominantly before clinical reasoning, while consequences are the outcomes thereof, such as a patient management plan (Huhn et al., 2018). Antecedents to clinical reasoning included the clinician's intuition and knowledge, the patient's needs, and considerations of the biopsychosocial model (Huhn et al., 2018), similar to our study. Intuition, patient and therapist perspectives, flexibility in thinking, and reflection were attributes described in the study. The similarities of elements and processes of clinical reasoning described by Huhn et al. (2018) and in our Delphi study, adds confidence to the results of this study.

\section{Implications}

We developed a model to provide a framework for teaching clinical reasoning skills (Figure 1) based on the findings of this study. The model places the patient, student and educator in the centre or core, namely collecting the patient-specific data; continuously interpreting and analysing the information from multiple domains; and planning, applying and modifying management (Table 2, numbers 6 and 7). Those processes are situated within the external context of the patient, such as the clinical environment, health policies, available resources, support and safety (Table 2, number 8). During the undergraduate programme, the student learns to link theory (knowledge), practice and accumulated experiences using various reasoning methods, models and reflective practice (collectively, the antecedents for clinical reasoning) (Table 2, numbers 2-5). The student (and the educator) constantly move from the "core" (the interaction with the patient) to the clinical context and external environment, surrounding the reasoning methods with progressively increasing knowledge and experience. Increasing levels and complexity of skills and knowledge should be demonstrated at a greater frequency and with increasing autonomy across the four years of study, alongside a decreasing level of supervision and educational scaffolding (Delany \& Golding, 2014).

The results of the current study are not definitive of clinical practice, as relevant knowledge and healthcare models and policies are constantly evolving. The results consider factors that influence clinical reasoning, and therefore provide a context for physiotherapy educators' definition and understanding at the time of the study. Continual reassessment and revision of teaching methods are needed to maintain a current perspective. Since completion of this study, the WHO ICF model has been 


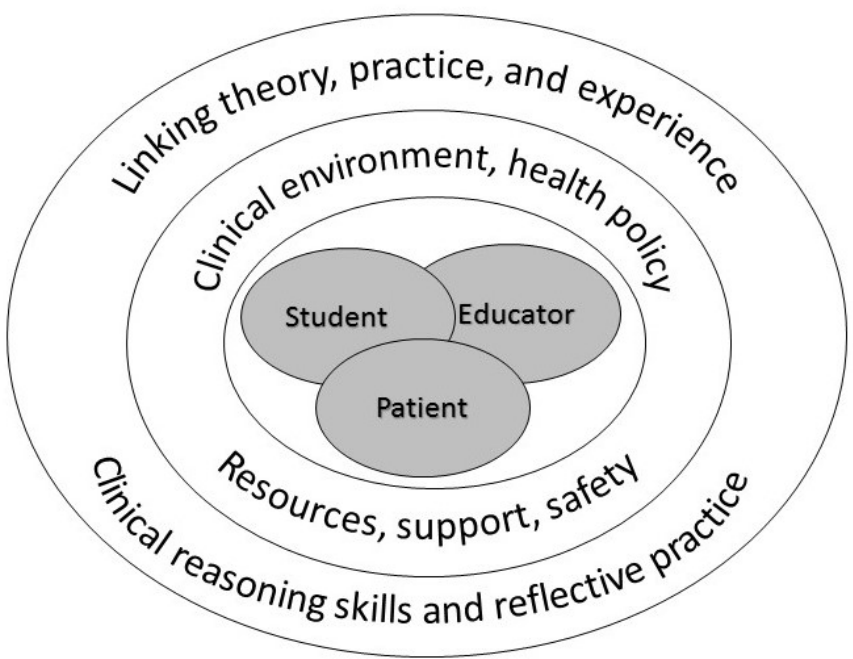

Figure 1. Proposed framework for clinical reasoning skills across undergraduate study in physiotherapy

applied as a biopsychosocial framework across all fields of physiotherapy in our undergraduate programme. Support for such implementation is also found in the health professional education literature (Campbell, Guptill, Stephenson, \& Campbell, 2006; Fayed, Gorter, \& MacDermid, 2016; Jones, 2011; Jones, 2019). Furthermore, considering the context of New Zealand, the Te Whare Tapa Whā model of health care (Ministry of Health, 2017) is applied from the start of Year 2 to emphasise clinical reasoning and practice centred on the holistic health and well-being of the person.

While a common teaching resource has not resulted directly from this research, the study has led to consensus about what elements need to be included in teaching. The study also increased the awareness of the range of different approaches and tools that are used in teaching by staff. Besides exposure to clinical practice, development of teaching resources applicable across laboratory and clinical teaching are required. For example, strategies such as case-based learning and continuous reflection facilitate the development of "fast" thinking (Carvalho et al., 2017; Peters et al., 2017). Clear communication and collaboration across all educators (lecture-, laboratory- and clinical-based teaching) in terms of approaches to teaching such skills will facilitate student acquisition of clinical reasoning skills in various contexts. It is anticipated that raising awareness of the different approaches may increase the willingness of staff to work towards a more unified approach to teaching and learning opportunities for students, not only at the University of Otago but also in other physiotherapy programmes.

Methodological considerations

All educators associated with the School of Physiotherapy were invited to participate. The use of the Delphi method and the focus groups ensured an inclusive approach. Only 11 respondents replied during Round 1 . However, the opportunity was provided during Rounds 2 and 3 to add additional comments or items. This project enabled information and resources to be shared amongst colleagues working in different geographical areas and across the spectrum of physiotherapy fields. With changing numbers of clinical supervisors and variability in individual teaching commitments, it was impossible to confirm the total population, and thus the response rate cannot be defined.

\section{CONCLUSION}

This study enabled physiotherapy educators to share information across their different geographical and contextual areas, and to reach consensus on elements considered important for teaching clinical reasoning. The resulting model placed the patient, student and educator at the core of the clinical reasoning framework. This core also encompassed the interpretation and analyses of information from multiple domains and planning ongoing modification of patient management. Those processes were embedded within the patient's clinical environment; current health policy; and available resources, support and safety. Within the model of the clinical reasoning framework, the core and the clinical environment were surrounded by the student increasingly being able to integrate theory and clinical practice, different reasoning skills, reflection and experience. The results highlight the multi-dimensional factors influencing the clinical reasoning processes. There is a clear need to scaffold students' development towards demonstrating clinical reasoning at the level expected for entry-level practice to the profession.

\section{KEY POINTS}

1. Clinical reasoning is an ongoing, complex and systematic process that is collaborative and interactive.

2. Hypothetico-deductive reasoning and the WHO ICF model were highly rated as suitable frameworks for clinical reasoning for undergraduate physiotherapy students.

3. The study identified the elements considered important by educators for teaching clinical reasoning to undergraduate physiotherapy students. These were (1) A patient-centred, collaborative approach; (2) Patient-related factors, such as beliefs, culture, social factors, physical, mental and healthrelated status, decision-making ability, and safety; (3) Physiotherapy-professional and person-specific knowledge, integrating theory and experiences from clinical practice; and (4) Contextual factors, such as the patient's environment, current health policies, resources and best available evidence.

\section{ACKNOWLEDGEMENTS}

We thank all colleagues who participated in this study for sharing their views, and our research assistant, David Jackson, who patiently managed the Delphi survey questionnaires and data.

\section{PERMISSIONS}

The study was approved by the University of Otago Human Ethics Committee (ref: D14/096).

\section{DISCLOSURES}

This study was supported by a grant from the Committee for the Advancement of Learning and Technology (CALT), University of Otago. 


\section{ADDRESS FOR CORRESPONDENCE}

Associate Professor Gisela Sole, Centre for Health, Activity and Rehabilitation Research, School of Physiotherapy, University of Otago, PO Box 56, Dunedin 9054, New Zealand. Telephone: +64 3479 7936. Email: gisela.sole@otago.ac.nz

\section{REFERENCES}

Ahlsen, B., Mengshoel, A. M., Bondevik, H., \& Engebretsen, E. (2018). Physiotherapists as detectives: Investigating clues and plots in the clinical encounter. Medical Humanities, 44(1), 40-45. https://doi.org/10.1136/ medhum-2017-011229

Ajjawi, R., \& Higgs, J. (2012). Core components of communication of clinical reasoning: A qualitative study with experienced Australian physiotherapists. Advances in Health Science Education, 17(1), 107-119. https://doi.org/10.1007/s10459-011-9302-7

Ajjawi, R., \& Smith, M. (2010). Clinical reasoning capability: Current understanding and implications for physiotherapy educators. Focus on Health Professional Education: A Multidisciplinary Journal 12(1), 60-73. Retrieved from https://search.informit.com.au/documentSummary; dn $=575$ 051740584589; res=IELNZC

Brooks, J., McCluskey, S., Turley, E., \& King, N. (2015). The utility of template analysis in qualitative psychology research. Qualitative Research in Psychology, 12(2), 202-222. https://doi.org/10.1080/14780887.2014.95 5224

Brydges, R., Dubrowski, A., \& Regehr, G. (2010). A new concept of unsupervised learning: Directed self-guided learning in the health professions. Academic Medicine, 85(10), S49-55. https://doi.org/10.1097/ ACM.0b013e3181ed4c96

Campbell, W. N., Guptill, C. A., Stephenson, F. F., \& Campbell, K. E. (2006). A conceptual model for interprofessional education: The international classification of functioning, disability and health (ICF). Journal of Interprofessional Care, 20(3), 235-245. https://doi org/10.1080/13561820600718139

Carvalho, D. P. S. R. P., Azevedo, I. C., Cruz, G. K. P., Mafra, G. A. C., Rego, A. L. C., Vitor, A. F. . . . Ferreira Júnior, M. A. (2017). Strategies used for the promotion of critical thinking in nursing undergraduate education: A systematic review. Nurse Education Today, 57, 103-107. https://doi. org/10.1016/j.nedt.2017.07.010

Chipchase, L. S., Buttrum, P. J., Dunwoodie, R., Hill, A. E., Mandrusiak, A \& Moran, M. (2012). Characteristics of student preparedness for clinical learning: Clinical educator perspectives using the Delphi approach. BMC Medical Education, 12, 112. https://doi.org/10.1186/1472-6920-12-112

Christensen, N., Black, L., Furze, J., Huhn, K., Vendrely, A., \& Wainwright, S (2017). Clinical reasoning: survey of teaching methods, integration, and assessment in entry-level physical therapist academic education. Physical Therapy, 97(2), 175-186. https://doi.org/10.2522/ptj.20150320

Colthart, I., Bagnall, G., Evans, A., Allbutt, H., Haig, A., Illing, J., \& McKinstry, B. (2008). The effectiveness of self-assessment on the identification of learner needs, learner activity, and impact on clinical practice. Medical Teacher, 30(2), 124-145. https://doi.org/10.1080/01421590701881699

Cruz, E. B., Moore, A. P., \& Cross, V. (2012). A qualitative study of physiotherapy final year undergraduate students' perceptions of clinical reasoning. Manual Therapy, 17(6), 549-553. https://doi.org/10.1016/j. math.2012.05.013

Delany, C., \& Golding, C. (2014). Teaching clinical reasoning by making thinking visible: An action research project with allied health clinical educators. BMC Medical Education, 14, 20. https://doi.org/10.1186/14726920-14-20

Fayed, N., Gorter, J. W., \& MacDermid, J. (2016). Enhancing interprofessional education and practice: Development and implementation of a new graduate-level course using the international classification of functioning, disability, and health. Journal of Interprofessional Care, 30(3), 385-387. https://doi.org/10.3109/13561820.2016.1139557
Golding, C., Wilkinson, T. J., \& Gamble Blakey, A. (2018). Cultivating critical thinkers. In C. Delany \& E. Molloy (Eds.), Learning and teaching in clinical contexts (pp. 29-44). Chatswood, Australia: Elsevier.

Gruppen, L. D. (2017). Clinical reasoning: Defining it, teaching it, assessing it, studying it. Western Journal of Emergency Medicine, 18(1), 4-7. https:// doi.org/10.5811/westjem.2016.11.33191

Hasson, F., Keeney, S., \& McKenna, H. (2000). Research guidelines for the Delphi survey technique. Journal of Advanced Nursing, 32(4), 1008-1015. https://doi.org/10.1046/j.1365-2648.2000.t01-1-01567.x

Higgs, J., \& Jones, M. A. (2008). Clinical decision making and multiple problem spaces. In J. Higgs, M. A. Jones, S. Loftus, \& N. Christensen (Eds.), Clinical reasoning in the health professions (3rd ed., pp. 3-17). Butterworth Heinemann.

Hoogenes, J., Mironova, P., Safir, O., McQueen, S. A., Abdelbary, H., Drexler M., ... Sonnadara, R. R. (2015). Student-led learning: A new teaching paradigm for surgical skills. The American Journal of Surgery, 209(1), 107114. https://doi.org/10.1016/j.amjsurg.2014.08.037

Hsu, C. C., \& Sandford, B. A. (2007). The Delphi technique: Making sense of consensus. Practical Assessment, Research \& Evaluation, 12(10), 1-8. Retrieved from https://pareonline.net/pdf/v12n10.pdf

Huhn, K., Gilliland, S. J., Black, L. L., Wainwright, S. F., \& Christensen, N. (2018). Clinical reasoning in physical therapy: A concept analysis. Physical Therapy. Advanced online publication. https://doi.org/10.1093/ptj/pzy148

Jones, L. E. (2011). Introducing the ICF: the development of an online resource to support learning, teaching and curriculum design. Physiotherapy, 97(1), 55-58. https://doi.org/10.1016/j.physio.2010.10.001

Jones, M. A. (2019). Clinical reasoning: fast and slow thinking in musculoskeletal practice. In M. A. Jones \& D. A. Rivett (Eds.), Clinical reasoning in musculoskeletal practice (2nd ed., pp. 2-31). Edinburgh: Elsevier

Kahneman, D. (2011). Thinking, fast and slow. New York: Farrar, Straus and Giroux.

Keeney, S., Hasson, F., \& McKenna, H. (2011). The Delphi technique. In S. Keeney, F. Hasson, \& H. McKenna (Eds.), The Delphi technique in nursing and health research (pp. 1-17). Oxford: Wiley-Blackwell. https://doi. org/10.1002/9781444392029.ch1

Kidd, M. O., Bond, C. H., \& Bell, M. L. (2011). Patients' perspectives of patient-centredness as important in musculoskeletal physiotherapy interactions: A qualitative study. Physiotherapy, 97(2), 154-162. https://doi. org/10.1016/j.physio.2010.08.002

Langridge, N., Roberts, L., \& Pope, C. (2015). The clinical reasoning processes of extended scope physiotherapists assessing patients with low back pain. Manual Therapy, 20(6), 745-750. https://doi.org/10.1016/j. math.2015.01.005

Langridge, N., Roberts, L., \& Pope, C. (2016). The role of clinician emotion in clinical reasoning: Balancing the analytical process. Manual Therapy, 21, 277-281. https://doi.org/10.1016/j.math.2015.06.007

Levett-Jones, T., Hoffman, K., Dempsey, J., Jeong, S. Y.-S., Noble, D., Norton, C. A., ... Hickey, N. (2010). The 'five rights' of clinical reasoning: An educational model to enhance nursing students' ability to identify and manage clinically 'at risk' patients. Nurse Education Today, 30(6), 515-520. https://doi.org/10.1016/j.nedt.2009.10.020

McMahon, S., Cusack, T., \& O'Donoghue, G. (2013). Barriers and facilitators to providing undergraduate physiotherapy clinical education in the primary care setting: A three-round Delphi study. Physiotherapy, 100(1), 14-19. https://doi.org/10.1016/j.physio.2013.04.006

Ministry of Health (2017). Māori health models - Te Whare Tapa Whā. Retrieved from https://www.health.govt.nz/our-work/populations/maorihealth/maori-health-models/maori-health-models-te-whare-tapa-wha

O'Connell, J., Gardner, G., \& Coyer, F. (2014). Beyond competencies: Using a capability framework in developing practice standards for advanced practice nursing. Journal of Advanced Nursing, 70(12), 2728-2735. https:// doi.org/10.1111/jan.12475 
Patton, N., Higgs, J., \& Smith, M. (2018). Clinical learning spaces:

Crucibles for practice development in physiotherapy clinical education.

Physiotherapy Theory and Practice, 34(8), 589-599. https://doi.org/10.108 0/09593985.2017.1423144

Peters, A., Vanstone, M., Monteiro, S., Norman, G., Sherbino, J., \& Sibbald, M. (2017). Examining the influence of context and professional culture on clinical reasoning through rhetorical-narrative analysis. Qualitative Health Research, 27(6), 866-876. https://doi.org/10.1177/1049732316650418

Rencic, J., Trowbridge, R. L., Fagan, M., Szauter, K., \& Durning, S. (2017). Clinical reasoning education at US medical schools: Results from a national survey of internal medicine clerkship directors. Journal of General Internal Medicine, 32(11), 1242-1246. https://doi.org/10.1007/s11606-0174159-y

Swamy, M., Venkatachalam, S., \& McLachlan, J. (2014). A Delphi consensus study to identify current clinically most valuable orthopaedic anatomy components for teaching medical students. BMC Medical Education, 14(1), 230. https://doi.org/10.1186/1472-6920-14-230

Van den Bruel, A., Thompson, M., Buntinx, F., \& Mant, D. (2012). Clinicians' gut feeling about serious infections in children: Observational study. British Medical Journal, 345, e6144. https://doi.org/10.1136/bmj.e6144

World Health Organization (2002). Towards a common language for functioning, disability and health: The International Classification of Functioning, Disability and Health (ICF). Retrieved from https://www.who. int/classifications/icf/icfbeginnersguide.pdf 